\title{
A survey on the effects of institutional ownership, internal audit and non-executive board members on forecasting crashes: Evidence from Tehran Stock Exchange
}

\author{
Mostafa Sohouli Vahed ${ }^{\mathrm{a}^{*}}$ and Mohammad Kheiri ${ }^{\mathrm{b}}$
}

${ }^{a}$ Masters student, Department of Accounting, Fars Science and Research Branch, Islamic Azad University (IAU), Fars, Iran ${ }^{b}$ Assistant. Prof. \& Faculty Member, Department of Accounting, Fars Science and Research Branch, Islamic Azad University (IAU), Fars, Iran

\section{H R O N I C L E}

\section{Article history:}

Received June 4, 2014

Accepted 8 October 2014

Available online

October 92014

Tehran Stock Exchange

Corporate strategic system

Stock price crash

Income management

Stock exchange negative

coefficient of skewedness

\begin{abstract}
A B S T R A C T
This paper presents an empirical investigation to study the effects of institutional ownership, internal audit system, the number of non-executive board members and having differentiation between chair and general managers' responsibilities on the likelihood of stock price crash on 110 listed firms on Tehran Stock Exchange over the period 2004-2011. The study uses Chen' model (2001) [Chen, J., Hong, H., \& Stein, J. C. (2001). Forecasting crashes: Trading volume, past returns, and conditional skewness in stock prices. Journal of Financial Economics, 61(3), 345-381.] to perform the investigation. Based on the results of the survey, there is a negative and meaningful relationship between stock price crash and institutional ownership when the level of significance is ten percent. In addition, as the number of non-executive board members increases, the chance of stock price crash decreases when the level of significance is five percent. However, separation between the responsibility of chair and general managers did not seem to influence on stock price and also having internal audit system had no impact on the likelihood of stock price change.
\end{abstract}

\section{Introduction}

Firms as economic units always seek for higher incomes achieving higher wealth and properties. Financial statements are considered as the primary sources for performance management. However, there are some evidences such as Enron, which indicate that financial reports could be manipulated and any investment decision could face unfavorable consequences. In some cases, lack of confidence may lead to stock price crash. Stock price crash is normally recognized as sudden and negative appeal in investors' expectations about the performance of market (Lotfi, 2011).

Stock price crash phenomena usually occurs due to bubble in firm stock price and because of management actions like bad news issuance delay, fast good news issuance (income management), tax escape, continuous projects with current negative value, lack of clear financial data. Biased supply of accounting data results in some restrictions for management change taking behavior control. So, 
one of the most significant implications to prevent such mentioned problems is to have corporate management observations, and differentiate economical units from their ownership and finally to preserve investors and individuals' rights. Corporate strategic system mechanisms appropriate establishment is the fundamental action in order to optimal usage of resources, answer enhancement, clarity, justice, and all companies' rights preserved and result in management systems correct alignment (Yazdi, 2011).

This research aims to study the relationship between corporate strategic system and stock price crash phenomenon. The study uses methods originally developed by Hutton et al. (2009) and Chen et al. (2001) to measure stock piece crash phenomenon and studies corporate strategic systems implications. The study uses institutional stockholders' ownership percentage, directorate nonoblique members percentage, differentiate general manager duties from chairman, and internal audit measures.

\section{Literature Review}

\subsection{Corporate governance}

Corporate governance is a set of management and control mechanisms of firms. Corporate governance system specify responsibilities and right distribution of different firms' individuals such as managers, employees, stockholders and other logical and real characteristics influenced by firms' activities. This system has regulations and trends in order to determine decision making process in firms such as goal setting. Determination of goal achieving tools and control system design have close relationship with the ways financial resource suppliers are equipped in order to reach return insurance. Corporate governance system is a set of specifications, structures, processes and cultural norms so that companies by obeying them could achieve clarity in work processes, answer to individuals' concerns. The mechanisms are different from one company to another one. Corporate strategic system (commercial unit strategic system) consists of some responsibilities and trends applied by directorate and oblique managers in order to determine the strategic way ensured achieving goals, risk control and responsible consumptions of resources. Corporate strategic system aim to achieve following goals: 1.answer, 2.clarity, 3.justice, 4.individuals right preservation

\subsection{Stock Price Crash}

There has been a growing concern on stock price crash phenomenon because of specific events such as financial turmoil in 2008 as well as bankruptcies of big companies like world.com, Enron. This phenomenon is vital for finance market analyzers and investors, accounting professional societies, and stock exchange managers. According to investor's points of view, this phenomenon is important because it is always useful to know firm specific features to predict price severe fluctuations in particular stock price crash for stock balance and risk management. According to Sunder (2010), the important point in relationship with severe loss risk deviated from stock price crash is that, despite risks associated with stock price systematic fluctuation, such loss never decreases through diversification of stock basket. Thus, the increase in market crash results in investors' pessimism about investments in stock exchange market and finally results in exclusion of investment resources through them from stock exchange market. Thus, knowing causes of this phenomenon, finding strategies in order to prevent such phenomena in finance market and models to predict the phenomena are very important for finance market regulators who are seeking the market flourish.

Thus, this phenomenon always gain attention of accounting professional societies and this case is one of the most important information requirements of decisions makers in association with appropriate decisions making in investment affair. Always, finding features results in investor's evaluation improvement of phenomena occurrence probability in firms finance report. One of the most important issues focused by references is associated with standards setting in accounting. This issue asks 
accounting professional societies to find fields of management misuse of accounting and looks for control strategies of this field.

The existing literature could be divided into two categories of micro and macro levels. In micro level, stock price crash phenomena are studied in firms' levels and the studies focus on finding stock price crash causes, finding prediction models, and strategies in order to prevent such phenomena but, in macro level, researchers are interested in issues using market information.

\section{Review of Literature}

\subsection{External Literature Review}

Some studies indicate firms with higher corporate governance rate show higher income payment and there is a stronger negative relationship between growth and dividends in firms with stronger corporate governance. Others compared financial statements before and after Asian financial crisis and reported a reverse relationship between corporate ownership and dividends before crisis while the relationship was changed to positive one after the crisis happened.

Liu and Lu (2007) investigated the relationship between earnings management and corporate governance in China by introducing a tunneling perspective. They reported systematic differences in earnings management across the universe of China's listed companies over the period 1999-2005, and empirically showed that firms with higher corporate governance levels had lower levels of earnings management. They also studied two China-specific situations, in which the listed firms had strong incentives to manage earnings in order to meet certain return on equity thresholds, and earnings management indicated to be the most conspicuous. They identified tunneling evidence for each and their empirical findings strongly suggested that agency conflicted between controlling shareholders and minority investors' account for a significant portion of earnings management in China's listed firms. Hutton et al. (2009) studied the relationship between financial account clarity, correlation between firm financial data and stock price and stock price crash phenomena in firm level. The research results indicated that lack of accounting data clarity could result in less changes of stock price due to new financial data disclosure.

Gugler and Yurtoglu (2003) analyzed 736 dividend change announcements in Germany over the period 1992-1998 and reported substantially larger negative wealth impacts in the order of two percentage points for firms where the ownership and control structure made the expropriation of minority shareholders more likely than for other companies. The rent extraction hypothesis also had implications for the levels of dividends paid and they reported larger holdings of the largest owner to reduce, while larger holdings of the second biggest shareholder to increase the dividend pay-out ratio. Deviations from the one-share-one-vote rule due to pyramidal and cross-ownership structures were also associated with larger negative wealth effects and lower pay-out ratios. Kim and Zhang (2010) studied the relationship between conservative accounting and stock price crash in US market and reported that conservative accounting prevent bad news storage by managers and in turn it could decrease stock price sudden crash probability.

Mashayekh and Esmaili (2006) studied the relationship between income quality and some strategic principle aspects like directorate members ownership percentage and non-oblique managers number at stock market accepted firms due to strategic principals regulations (enacted). They reported that non-oblique managers and directors' ownership percentage as corporate strategic principals implications played insignificant role in Tehran Stock Market accepted firms' income quality promotion.

In other study, the relationship between corporate governance system implications and Tehran stock Exchange accepted firms' representative expenses was investigated and institutional investors' active and influential action seemed to influence on firm management decision making. Lotfi (2011) studied 
conservative accounting influence on stock price crash decline in Tehran Stock Exchange accepted firms. They reported strong evidences delivered to decrease conservativeness in firm financial reports, and their stock price crash risk probability significantly.

\section{Research methodology}

Theoretical fundamental setting was performed through library method and study of various books, articles, thesis and journals and then in order to collect data related to research variables it was used field study and software and compact disks. References of required data collection are firm's financial inventories. Collected data were modified and classified and analyzed through Excel and final analysis performed through SPSS software.

\subsection{Sample population}

By following restrictions for sample population and modification, sample was determined. This research selected sample includes firms with following requirements:

1. Accepted before financial year of 2004 in Tehran Stock Exchange,

2. Final year extinction is $20^{\text {th }}$ March,

3. Not belong to Tehran Stock Exchange omitted firms,

4. In studied span, financial span never faced changes,

5. Not belong to investment, insurance and financial dealer firms,

6. At least 6 months of year they show per month outcome,

7. Firm expected data must be available.

Based on the information, 110 firms over the period 2004-2011 have been selected.

\section{Research hypothesis}

In this research, based on theoretical fundamentals and literature background, the following hypothesis is considered.

Main hypothesis:

Corporate strategic system implications decrease stock price crash probabilities of firms listed on Tehran Stock Exchange.

In addition, the following four sub-hypotheses are considered for the proposed study of this paper.

First sub-hypothesis: as corporate owners percentage increase, the likelihood of stock price crash in firms listed on Tehran Stock Exchange decreases.

Second sub-hypothesis: as the number of non-executive board members increases, the likelihood of stock price crash in firms listed on Tehran Stock Exchange decreases.

Third sub-hypothesis: Having internal audit decreases the likelihood of stock price crash in firms listed on Tehran Stock Exchange decreases.

Fourth sub- hypothesis: differentiation between general manager and chair's duties reduces the likelihood of stock price crash in firms listed on Tehran Stock Exchange. 


\section{Studied variables}

\subsection{Dependent variables}

Dependent variable is a type of variable, which is changed according to independent variable. In this research, stock price crash is dependent variable. In order to compute stock price crash, the proposed study uses two models, which are briefly described next.

First model: The first model developed by Hutton et al. (2009) uses the following equations,

$r_{j, t}=\alpha_{j}+\beta_{1 j} r_{m, t-2}+\beta_{2 j} r_{m, t-1}+\beta_{3 j} r_{m, t}+\beta_{4 j} r_{m, t+1}+\beta_{5 j} r_{m, t+2}+\varepsilon_{j, t}$

$W_{j, t}=\operatorname{In}\left(1+\varepsilon_{j, t}\right)$

In Eq. (1), $r_{j, t}$ is pure monthly outcome of the firm $j$ at the month of $t$ and $r_{m, t}$ represents market monthly outcome, which is calculated based on market index. Eq. (1) considers the information of pre and post months to investigate the trend. Using the threshold of Eq. (2), $\varepsilon_{j, t}$, represents stock price outcome. According to Hutton et al. (2009), when $w<3 / 2$, we may expect stock price crash.

Second model: The second model is based on Chen et al. (2001) stock price crash model and the model uses skewness negative coefficient to predict the stock crash as follows,

$$
N C S K E W_{i t}=\left(n(n-1)^{3 / 2} \sum R_{i t}^{3}\right) /\left((n-1)(n-2)\left(\sum R_{i t}^{2}\right)^{3 / 2}\right)
$$

where $R_{i t}$ represents the sequence of de-meaned daily returns to stock $i$ in time $t$; and $n$ represents the number of observations on daily returns during the period. In measuring NCSKEW and any other moments, which depends on daily return data, Chen et al. (2001) drop any firm that has more than five missing data on daily returns in a given period. These daily "returns" are, more precisely, actually log changes in price. They use log changes as opposed to simple daily percentage returns because they help for a natural benchmark - if stock returns were log-normally distributed, then an NCSKEW measure based on log changes could have a mean of zero. We have also re-execute everything with an NCSKEW measure based instead on simple daily percentage returns, and none of our main results was affected.

\subsection{Independent variable}

Independent variable is a feature of social or physical environment, which accepts some values after selection or intervene by researcher to show its effect on other variable. Corporate governance is the independent variable and considers the following variables,

INST: Institutional stockholders share percent,

BRD_IND= non-executive board members,

INT_AUDIT= dummy variable, which is one in case of internal audit and 0, otherwise,

CEO_POWER= dummy variable, which is one if there is a difference between general manager's duties and chair and zero, otherwise.

\section{Research model}

In this research, the following relationships are used to examine the sub-hypotheses of the survey. First sub-hypothesis: For the first hypothesis of the survey, we use the following equations,

$$
\left.\operatorname{NCSKEW}_{i t+1}=\propto_{0}+\propto_{1} I_{N S_{i t}}+\sum_{q=2}^{m} \propto_{q}\left(q^{\text {th }} \text { Control Variables }\right)_{t}\right)+\varepsilon_{t}
$$


$\operatorname{Crash}_{i t+1}=\propto_{0}+\propto_{1} I N S_{i t}+\sum_{q=2}^{m} \propto_{q}\left(q^{\text {th }}\right.$ Control Variables $\left.t\right)+\varepsilon_{t}$

where $C R A S H_{i t+1}$ indicates stock price crash. If the firm experiences stock price crash once, the value of this component is equal to one and if the firm experiences two stock price crash, it is equal to 2, etc. $N C S K E W_{i t+1}$ is the next year stock outcome skewness coefficient. INST $T_{i t}$ represents institutional stockholders share percentage.

Second sub-hypothesis: The third hypothesis of the survey is as follows,

$\operatorname{NCSKEW}_{i t+1}=\propto_{0}+\propto_{1}$ BRD_ind $_{i t}+\sum_{q=2}^{m} \propto_{q}\left(q^{\text {th }}\right.$ Control Variables $\left.{ }_{t}\right)+\varepsilon_{t}$

Crash $_{i t+1}=\propto_{0}+\propto_{1}$ BRD_ind $i t+\sum_{q=2}^{m} \propto_{q}\left(q^{\text {th }}\right.$ Control Variables $\left.{ }_{t}\right)+\varepsilon_{t}$

where BRD_IND ${ }_{i t}$ represents non-oblique managers’ percentage.

Third sub-hypothesis: The third hypothesis of the survey is as follows,

$\operatorname{NCSKEW}_{i t+1}=\propto_{0}+\propto_{1}$ INT_Audit $_{i t}+\sum_{q=2}^{m} \propto_{q}\left(q^{\text {th }}\right.$ Control Variables $\left._{t}\right)+\varepsilon_{t}$

Crash $_{i t+1}=\propto_{0}+\propto_{1} I N T_{-}$Audit $\left.{ }_{i t}+\sum_{q=2}^{m} \propto_{q}\left(q^{\text {th }} \text { Control Variables }\right)_{t}\right)+\varepsilon_{t}$

where INT_AUDIT $T_{i t}$ is a dummy variable, which is one of the firm has internal audit and zero, otherwise.

Fourth sub-hypothesis: The last hypothesis of the survey is as follows,

$\operatorname{NCSKEW}_{i t+1}=\propto_{0}+\propto_{1}$ CEO_power $_{i t}+\sum_{q=2}^{m} \propto_{q}\left(q^{\text {th }}\right.$ Control Variables $\left._{t}\right)+\varepsilon_{t}$

Crash $_{i t+1}=\propto_{0}+\propto_{1}$ CEO_power p $_{i t}+\sum_{q=2}^{m} \propto_{q}\left(q^{\text {th }}\right.$ Control Variables $\left.{ }_{t}\right)+\varepsilon_{t}$

where CEO_POWER $R_{i t}$ is one if there is a difference between the duties of chair and general managers and zero, otherwise.

\section{Results}

\subsection{Results based on Hutton's model (2012).}

According to Hutton et al. (2012) model, when stock price crash frequencies is located in 3/2 standard deviation from the average, we may conclude that no stock price crash could be observed in Tehran Stock Exchange in accepted firms. Since there are not good evidences to support this claim, we therefore use Chen's model. 


\subsection{Results based on Chen et al. (2001) model}

\subsubsection{First sub-hypothesis}

According to the first hypothesis, as the percentage of institutional ownership increases, the likelihood of stock price crash in firms listed on Tehran Stock Exchange decreases. Table 1 demonstrates the results of our survey.

\section{Table 1}

The summary of testing the first sub-hypothesis

\begin{tabular}{lllll}
\hline F-value & Sig. & Variable & t-value & Sig. \\
\hline 3.204 & 0.000 & NCSKEW & 0.382 & 0.703 \\
Determination coefficient & 0.035 & INST & -1.659 & 0.098 \\
& & Durbin-Watson item & 1.914 \\
\hline
\end{tabular}

Thus, the model determination coefficient is equal to 0.035 that is $3.5 \%$ of dependent variable changes are influenced by independent variable. The significance level is 0.000 that is there is a linear (meaningful) relationship between dependent variables and independent variables. Institutional stockholders variable has negative and meaningful influence on research dependent variable. Thus, obtained results confirm the first hypothesis as the institutional stockholders ownership rate increases, stock price crash risk probability decreases and the first hypothesis with $90 \%$ confidence is confirmed.

\subsubsection{Second sub-hypothesis}

The second sub-hypothesis indicates that as the number of non-executive board members increases, the chance of stock price crash decreases. Table 2 shows the results of our survey.

\section{Table 2}

The summary of testing the second sub-hypothesis

\begin{tabular}{lllll}
\hline F-value & Sig. & Variable & t-value & Sig. \\
\hline 2.948 & 0.001 & NCSKEW & -.240 & 0.811 \\
Determination coefficient & 0.033 & BRD_INDit & 2.218 & 0.027 \\
& & Durbin-Watson item & & 1.906 \\
\hline
\end{tabular}

As we can observe from the results of Table 2, F-value as well as t-value are statistically significant and can conclude that as the rate of non-executive board members increases, the likelihood of stock price crash in firms listed on Tehran Stock Exchange decreases. Therefore, the second hypothesis of the survey is confirmed.

\subsubsection{Third sub-hypothesis}

Next, we investigate the role of having internal audit system on the likelihood of stock price crash. Table 3 summarizes the results of regression analysis, F-value is statistically significant, which leads us to conclude that internal audit decreases the likelihood of stock price crash in firms listed on Tehran Stock Exchange decreases. However, the results of t-student values are not statistically significant.

\section{Table 3}

Third sub-hypothesis test results

\begin{tabular}{lllll}
\hline F-value & Sig. & Variable & t-value & Sig. \\
\hline 2.994 & 0.001 & NCSKEW & -.268 & 0.788 \\
Determination coefficient & 0.033 & INA_AUDIT & 0.704 & 0.482 \\
\hline & & Durbin-Watson item & & 1.906 \\
\hline
\end{tabular}




\subsubsection{Fourth sub-hypothesis}

Finally, the last hypothesis of the survey investigates whether differentiation between general manager and chair's duties could reduce the likelihood of stock price crash in firms listed on Tehran Stock Exchange. The result of F-value statistics presented in Table 4 also confirms the last hypothesis of the survey. However, t-student values are not significant even at $10 \%$ confidence level. Therefore, there are some weak supports for this hypothesis.

\section{Table 4}

Fourth sub-hypothesis test results

\begin{tabular}{lllll}
\hline F-value & Sig. & Variable & t-value & Sig. \\
\hline 3.049 & 0.001 & NCSKEW & -.250 & 0.802 \\
Determination coefficient & 0.034 & CEO-POWER & 1.013 & 0.311 \\
& & Durbin-Watson item & & 1.905 \\
\hline
\end{tabular}

\section{Conclusion}

This paper has presented an empirical investigation to study the impacts of institutional ownership, internal audit system, the number of non-executive board members and having differentiation between chair and general managers' responsibilities on the likelihood of stock price crash on some firms listed on Tehran Stock Exchange. Using Chen' model (2001), the study has determined that there was a negative and meaningful relationship between stock price crash and institutional ownership when the level of significance was ten percent. In addition, as the number of non-executive board members increased, the chances of stock price crash seem to decrease but separation between the responsibility of chair and general managers did not seem to influence on stock price and also having internal audit system had no impact on the likelihood of stock price change.

\section{References}

Chen, J., Hong, H., \& Stein, J. C. (2001). Forecasting crashes: Trading volume, past returns, and conditional skewness in stock prices. Journal of Financial Economics, 61(3), 345-381.

Gugler, K., \& Yurtoglu, B. B. (2003). Corporate governance and dividend pay-out policy in Germany. European Economic Review, 47(4), 731-758.

Hutton, A. P., Marcus, A. J., \& Tehranian, H. (2009). Opaque financial reports, $\mathrm{R}^{2}$, and crash risk. Journal of Financial Economics, 94(1), 67-86.

Jin, L., \& Myers, S. C. (2006). $\mathrm{R}^{2}$ around the world: New theory and new tests. Journal of Financial Economics, 79(2), 257-292.

Kim, J. B., \& Zhang, L. (2010). Does accounting conservatism reduce stock price crash risk? Firmlevel evidence. Unpublished Working Paper, City University of Hong Kong.

Liu, Q., \& Lu, Z. J. (2007). Corporate governance and earnings management in the Chinese listed companies: A tunneling perspective. Journal of Corporate Finance, 13(5), 881-906.

Lotfi, M. (2011). Conservative accounting influence on stock price crash risk probability of Tehran stock market accepted firms. Masters’ Thesis. Economic Science University of Tehran.

Mashayekh, S.H., \& Esmaili, M. (2006). A study of relationship between income quality and some aspects of strategic principles at Tehran stock market accepted firms. Accounting and Auditing Studies, 45, 25-44.

Sunder, S. (2010). Riding the accounting train: from crisis to crisis in eighty years. In Presentation at the Conference on Financial Reporting, Auditing and Governance, Lehigh University, Bethlehem, $P A$.

Yazdi, D. (2011). Study of relationship between conservative accounting and corporate governance at Tehran stock market accepted firms. Masters’ Thesis. Economic Science University of Tehran. 